\title{
Evaluation of two morphometric methods of bone loss percentages caused by periodontitis in rats in different locations
}

\author{
Daniela Martins de SOUZA¹, Fernanda de Almeida PRADO², Marcela de Almeida PRADO², Rosilene Fernandes da \\ ROCHA ${ }^{3}$, Yasmin Rodarte de CARVALHO 4
}

1- DDS, MSc, PhD Professor, Discipline of Periodontology, Dental Course, Pindamonhangaba College (FAPI), Christian Life University Foundation,
Pindamonhangaba, SP, Brazil.
2- DDS, Dentist, São José dos Campos Dental School, São Paulo State University, São José dos Campos, SP, Brazil.
3- DDS, MSc, PhD Professor, Discipline of Pharmacology, São José dos Campos Dental School, São Paulo State University, São José dos Campos, SP,
Brazil.
4- DDS, MSc, PhD Professor, Discipline of Biopathology, São José dos Campos Dental School, São Paulo State University, São José dos Campos, SP, Brazil.

4- DDS, MSc, PhD Professor, Discipline of Biopathology, São José dos Campos Dental School, São Paulo State University, São José dos Campos, SP, Brazil.

Corresponding address: - Profa. Dra. Daniela Martins de Souza - Departamento de Biociências e Diagnóstico Bucal - Av. Engenheiro Francisco José Longo, 777 - Phone: (12) 3947-9034 - 12245-000 - Jardim São Dimas - São José dos Campos - SP - e-mail: danimart.voy@terra.com.br

Received: February 25, 2009 - Modification: February 17, 2010 - Accepted: April 9, 2010

\section{ABSTRACT}

bjective: The present study evaluated morphometrically bone loss percentages in experimental periodontitis in rats, comparing different locations (lingual mandible, palatal maxilla and buccal maxilla) and two evaluation methods (distance and area methods). Material and Methods: Ligatures were placed around the maxillary right second molar and around the mandibular right first molar in 14 female Wistar rats. The contralateral molars served as intragroup controls. After 4 weeks, the rats were sacrificed and their mandible and maxilla were removed. The specimens were dissected and stained with methylene blue dye. Bone loss was evaluated by two different methods on the surfaces of the defleshed jaw. In the first method, the distance from the cementoenamel junction (CEJ) to the alveolar bone crest was measured in the roots of teeth associated with ligature. In the second method, the area of bone loss was determined using the alveolar tissue bone, CEJ and the proximal region of roots associated with the ligature as reference. The data were converted to bone loss percentages caused by ligature: (ligated - unligated) x 100/ligated. Results: When comparing the distance and area methods, no statistically significant difference was observed $(p>0.05)$. Both methodologies indicated that the maxilla presented greater bone loss than the mandible and it was more accentuated on the buccal side than on the palatal side $(p<0.05)$. Conclusions: The findings of this study show that both the area and the distance methods can be used to evaluate bone loss caused by ligature placement in rats, and suggest applying the morphometric methodology to the maxilla on the buccal side.

Key words: Experimental studies. Methodology. Periodontal diseases. Rats.

\section{INTRODUCTION}

Periodontitis is characterized by the presence of inflammation and progressive destruction of supporting structures of the teeth, including the periodontal ligament, alveolar bone and gingival tissues ${ }^{14}$.

The use of rat models has been validated in the evaluation of pathogenesis of periodontal diseases ${ }^{28}$ and regarding the influence of risk factors, such as nicotine ${ }^{20}$, alcohol ${ }^{23-25}$ and diabetes ${ }^{13}$ on disease progression. The induction of periodontal disease in rats can be achieved in many ways. In numerous studies, the use of cotton ligatures is reported, involving the cervical portion of the maxillary second molar $1,2,6,7,10,17,22,23,25-27$ or the mandibular first molar ${ }^{3,4,9,13,19,20,24}$.

Previous studies have validated the use of morphometric analysis to evaluate alveolar bone loss in ligature-induced periodontitis in rats ${ }^{1,5-}$ $7,12,18,22,23,25,27$. According to Klausen ${ }^{15}$ (1991), this is the most appropriate methodology to measure periodontal bone loss in dissected rat maxillas. However, these analyses present different locations for evaluation and numerous measurement methods. Alveolar bone loss located on molar buccal 
and lingual faces can be quantified by measuring the linear distance of the cementoenamel junction (CEJ) from the alveolar bone crest $(A B C)$ in molar roots $6,8,16,17,21-23,25,27$. In addition, measurements of the area of bone loss using the alveolar bone tissue, the CEJ and the proximal region of roots as references has also been validated ${ }^{1,26}$, as has measuring the area of the exposed root $^{17}$.

The purpose of this study was to evaluate morphometrically the alveolar loss bone caused by experimental induction of periodontitis in rats, comparing different locations (lingual mandible, palatal maxilla and buccal maxilla) and methods (area and distance).

\section{MATERIAL AND METHODS}

\section{Animals}

Fourteen 4-month-old adult female Wistar rats weighing $300 \mathrm{~g}$ on average were used in the study. All rats were housed under similar conditions and received solid diet (Guabi Nutrilabor, Mogiana Alimentos, Campinas, SP, Brazil) and water ad libitum. The Institutional Animal Research Committee of São José dos Campos Dental School, São Paulo State University, São José dos Campos, $\mathrm{SP}$, Brazil, approved the research protocol.

\section{Periodontitis induction}

General anesthesia was induced by intramuscular administration with a solution of $13 \mathrm{mg} / \mathrm{kg}$ of $2 \%$ xylazine hydrochloride (Rompum, Bayer, São Paulo, $\mathrm{SP}$, Brazil) and $33 \mathrm{mg} / \mathrm{kg}$ of ketamine hydrochloride (Francotar, Virbac, Roseira, SP, Brazil). To induce periodontitis, cotton ligatures (Coats-Corrente, São Paulo, SP, Brazil) were placed around the cervix of the maxillary second molar and mandibular first molar, both on the right side, leaving the left side molars unligated to serve as controls.

After 4 weeks, the rats were sacrificed by decapitation, the mandibles and maxillas were removed and separated into right and left sides, and the specimens were fixed in $10 \%$ formalin solution.

\section{Morphometric analysis of alveolar loss bone}

The specimens were dissected very carefully to maintain their integrity. The procedure included immersion in sodium hypochlorite for $4 \mathrm{~h}$ and mechanical scavenging of the remaining tissue. Next, the specimens were stained with methylene blue dye $(1 \mathrm{~g} / 100 \mathrm{~mL})$ for $1 \mathrm{~min}$ to demarcate the CEJ.

The specimens were examined under stereomicroscopy. To obtain sufficient reproducibility of the alignment of the image, the buccal cusp tip of the first and second molars should be superimposed on the corresponding lingual/palatal cusp tip. Thus, it is not possible to visualize the occlusal surface.

The image was digitalized at $25 x$ magnification for the buccal and palatal sides of the maxilla and for the lingual side of the mandible. Measurements were made on the maxillary second molar and mandibular first molar three times using Image Tool v.3.0 image-analysis software (UTHSCSA, San Antonio, TX, USA), and the mean values were used in statistical analysis. All measurements were made in a blinded fashion to the group to which the rat belonged.

The area method was defined by delimitation of the area of bone loss, using the alveolar bone crest $(A B C)$, the CEJ and the proximal region of roots as reference. The distance method applied by Crawford, Taubman and Smith ${ }^{8}$ (1978) on digitalized images was used to perform linear measurements from the $C E J$ to the $A B C$, on half of each root following the axis. Three measurements were obtained for the mandibular first molar (lingual) and four for the maxillary second molar, two each for the buccal and palatal sides. Both methods can be observed in Figure 1 for the buccal maxilla, in Figure 2 for the palatal maxilla, and in Figure 3 for the lingual mandible.

The bone loss values caused by periodontitis were transformed into bone loss percentages. The percentage of periodontal bone loss (PBL) was measured by two methods (area and distance)

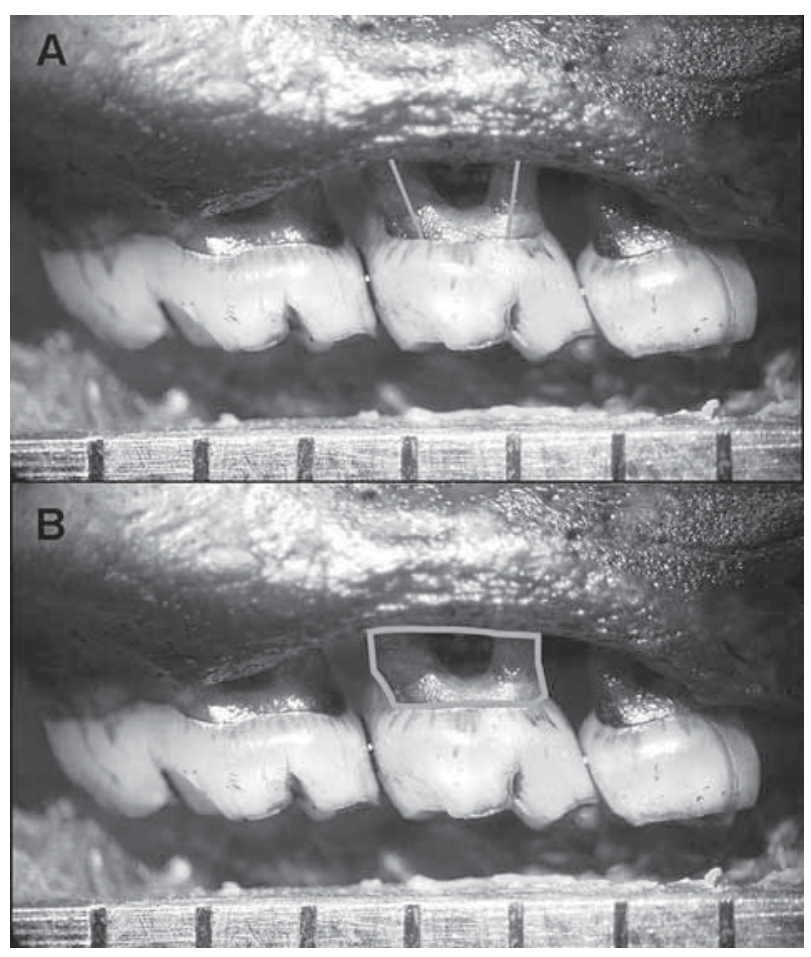

Figure 1- Photograph of alveolar bone loss evaluated morphometrically by measuring the linear distance between the cementoenamel junction and alveolar bone crest at two buccal sites on the maxillary second molar (A). The area method was defined by delimitation of the area of bone loss using the alveolar bone crest, the cementoenamel junction and the proximal region of roots of the maxillary second molar on the buccal side as references (B). Original magnification: x 25 


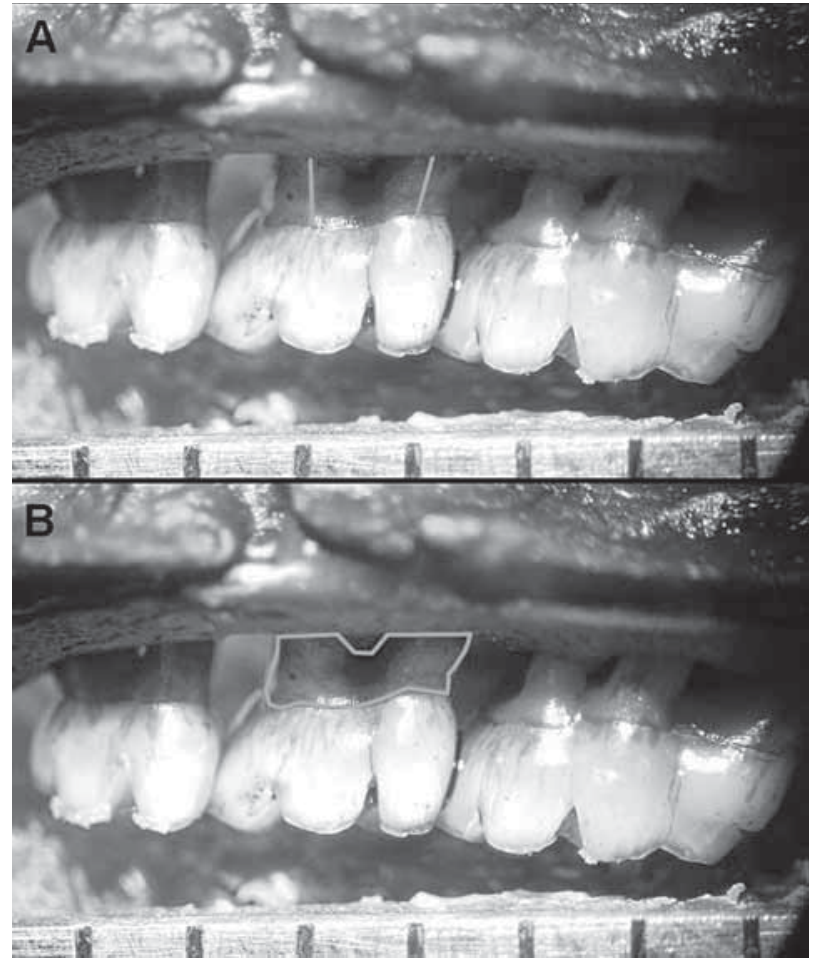

Figure 2- Photograph of alveolar bone loss evaluated morphometrically by measuring the linear distance between the cementoenamel junction and alveolar bone crest at two palatal sites on the maxillary second molar (A). The area method was defined by delimitation of the area of bone loss using the alveolar bone crest, the cementoenamel junction and the proximal region of roots of the maxillary second molar on the palatal side as references (B). Original magnification: $x 25$

in teeth with (LIG) and without ligature (UNLIG) for the palatal and buccal maxilla, and the lingual mandible. $\mathrm{PBL}$ was determined using the following equation: $\mathrm{PBL}=(\mathrm{LIG}-\mathrm{UNLIG}) \times 100 / \mathrm{LIG}$.

\section{Reproducibility}

Prior to the statistical analyses, the intraexaminer reproducibility was checked by evaluating two sets of measurements of all specimens with a 1-week interval. Paired $t$ test statistical analysis showed no differences between the mean values obtained for the area method $(p=0.4179)$ and the distance method $(p=0.3273)$. Additionally, Pearson's correlation coefficient was obtained between the two sets of measurements and revealed a very high correlation in both the area (99\%: $r=0.99986$, $\mathrm{p}=0.000)$ and distance methods (99\%: $r=0.9986$, $p=0.000)$.

\section{Statistical analysis}

Data were expressed as mean values and standard deviation of percentage (\%) of periodontal bone loss ( $\mathrm{mm}$ or $\mathrm{mm}^{2}$ ). The $t$ test for independent variables $(\alpha=0.05)$ was used for comparisons between the area and distance methods. Oneway ANOVA $(\alpha=0.05)$ and the Tukey's test for subsequent multiple comparisons $(\alpha=0.05)$

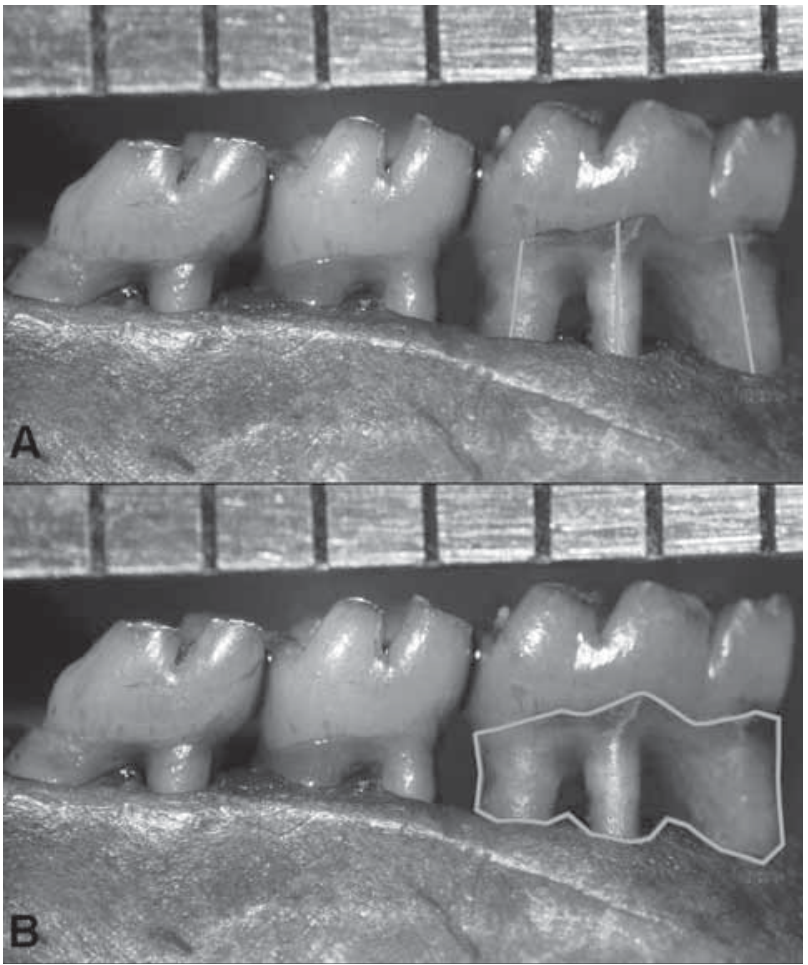

Figure 3- Photograph of alveolar bone loss evaluated morphometrically by measuring the linear distance between the cementoenamel junction and alveolar bone crest at three lingual sites on the mandibular first molar (A). The area method was defined by delimitation of the area of bone loss using the alveolar bone crest, the cementoenamel junction and the proximal region of roots of the mandibular first molar on the lingual side as references (B). Original magnification: $\times 25$

were used to determine significant differences in periodontal bone loss between the locations analyzed.

\section{RESULTS}

Morphometric analysis showed no significant differences among PBL values $(p>0.05)$ for the area and distance methods for three locations (buccal maxilla: $p=0.6981$; palatal maxilla: $p=0.0816$ and lingual mandible: $p=0.3789$ ).

Evaluating the percentage of PBL derived from the cotton ligature insertion in different locations, there was showed significant differences among PBL values $(p<0.05)$. Analysis revealed a greater percentage of PBL in the maxilla, bone loss was more accentuated on the buccal side than the palatal side $(p<0.05)$. On the lingual side of the mandible, there was a lower percentage in PBL values (Table 1 ). 
Table 1- Mean and standard deviation of alveolar bone loss (\%) at the evaluation location

Area method

\section{Buccal maxilla \\ Palatal maxilla}

Lingual mandible
$64.60(7.13) a^{* *}$

$47.02(2.54) \mathrm{b}$

$28.67(9.13) \mathrm{c}$
Distance method

$60.83(6.94) A^{* * *}$

$43.11(4.93) \mathrm{B}$

$22.74(8.72) \mathrm{C}$ p*

0.1902

0.0638

0.1643

* independent sample $t$ test $(p<0,05)$. Lower case letters** should be considered in the area method column and capital letters ${ }^{* * *}$ should be considered in the distance method column (ANOVA and Tukey, $p<0.05$ ). Means followed by different letters differ statistically

\section{DISCUSSION}

The most commonly used teeth for periodontitis induction in rats are the maxillary second molar $1,2,6,7,10,17,22,23,25-27$ and the mandibular first molar $3,4,9,13,19,20,24$, both of which were evaluated in the present study.

Kuhr, et al. ${ }^{17}$ (2004) verified that the presence of a cotton ligature caused bone loss, which is detectable by morphometric analysis on day 15 after its placement. Subsequent observation verified the stagnation of bone loss progression up to day 60 . Based on that study ${ }^{17}$, it can be concluded that the ligature must remain in place for a minimum of 15 days and the experimental period can range from 15 to 60 days.

Regarding the period of ligature placement, several studies in rats used 30 days for periodontitis induction in the maxilla and mandible ${ }^{10,11,19,20}$. This period was very similar to that used in the present work of four weeks.

Alveolar bone loss in rats can be caused by physiological remodeling or periodontitis induction ${ }^{15}$. The present study only identified the effects of ligature on the alveolar bone because the bone loss values obtained in unligated teeth (physiological bone remodeling) were subtracted from the bone loss values obtained in the presence of ligature (periodontitis induction effects). The aim of this methodology was to define the amount of bone loss caused by periodontitis and to determine which location was more sensitive to the evaluation methods. The results revealed greater bone loss in the maxilla on the buccal side than on the palatal side, and in the lingual side of the mandible.

The present study showed that both the area and the distance morphometric methods could be used, as there was no significant difference between each other regarding bone loss caused by periodontitis. However, when Kuhr, et al. ${ }^{17}$ (2004) compared both methods on the buccal maxilla, their results suggested that the distance method was preferable to the area method. Moreover, the linear method has long been studied 8,16 and has recently been more commonly used for morphometric analyses of alveolar bones in dissected skulls $7,12,22,23,25,27$.

\section{CONCLUSION}

The present study showed that both area and distance measurements can be used to evaluate bone loss caused by ligature-induced periodontitis in rats, and suggests applying the morphometric methodology to the maxilla on the buccal side.

\section{REFERENCES}

1- Anbinder AL, Prado Mde A, Spalding M, Balducci I, Carvalho YR, Rocha RF. Estrogen deficiency and periodontal condition in rats: a radiographic and macroscopic study. Braz Dent $J$. 2006;17(3):201-7.

2- Bain JL, Lester SR, Henry WD, Bishop CM, Turnage AA, Naftel $\mathrm{JP}$, et al. Comparative gender differences in local and systemic concentrations of pro-inflammatory cytokines in rats with experimental periodontitis. J Periodontal Res. 2009;44(1):13340.

3- Benatti BB, Nogueira-Filho GR, Diniz MC, Sallum EA, Sallum AW, Nociti FH Jr. Stress may enhance nicotine effects on periodontal tissues. An in vitro study in rats. J Periodontal Res. 2003;38(3):351-3.

4- Bezerra JP, Silva LR, Alvarenga Lemos VA, Duarte PM, Bastos MF. Administration of high doses of caffeine increses alveolar bone loss in ligature-induced periodontitis in rats. J Periodontol. 2008;79(12):2356-60.

5- Bezerra MM, Brito GA, Ribeiro RA, Rocha FA. Low-dose doxycycline prevents inflammatory bone resorption in rats. Braz J Med Biol Res. 2002;35(5):613-6.

6- Björnsson MJ, Velschow S, Stoltze K, Havemose-Poulsen A, Schou S, Holmstrup P. The influence of diet consistence, drinking water and bedding on periodontal disease in Sprague-Dawley rats. J Periodontal Res. 2003;38(6):543-50.

7- Cavaghi J, Soletti AC, Gaio EJ, Rösing CK. The effect of dexamethasone in the pathogenesis of ligature-induced periodontal disease in Wistar rats. Braz Oral Res. 2005;19(4):2904.

8- Crawford JM, Taubman MA, Smith DJ. The natural history of periodontal bone loss in germfree and gnotobiotic rats infected with periodontopathic microorganisms. J Periodontol Res. $1978 ; 13(4): 316-25$.

9- Fernandes LA, Almeida JM, Theodoro LH, Bosco AF, Nagata MJ, Martins TM, et al. Treatment of experimental periodontal disease by photodynamic therapy in immunosuppressed rats. J Clin Periodontol. 2009;36(3):219-28.

10- Fernandes MI, Gaio EJ, Oppermann RV, Rados PV, Rösing CK. Comparison of histometric and morphometric analyses of bone height in ligature-induced periodontitis in rats. Braz Oral Res. 2007;21(3):216-21.

11- Gaspersic R, Stiblar-Martincic D, Osredkar J, Skaleric U. Influence of subcutaneous administration o recombinant TNFalpha on ligature-induced periodontitis in rats. J Periodontal Res. 2003;38(2):198-203.

12- Grauballe MC, Bentzen BH, Björnsson M, Moe D, Jonassen TE, Bendtzen $\mathrm{K}$, et al. The effect of spironolactone on experimental periodontitis in rats. J Periodontal Res. 2005;40(3):212-7.

13- Holzhausen M, Garcia DF, Pepato MT, Marcantonio E Jr. The influence of short-term diabetes mellitus and insulin therapy on alveolar bone loss in rats. J Periodontal Res. 2004;39(3):188-93. 14- Kinane DF. Causation and pathogenesis of periodontal disease. Periodontol 2000. 2001;25:8-20. 
15- Klausen B. Microbiological and immunological aspects of experimental disease in rats: a review article. J Periodontol. $1991 ; 62(1): 59-73$.

16- Klausen B, Evans RT, Sfintescu C. Two complementary methods of assessing periodontal bone level. Scand J Dent Res. 1989;97(6):494-9.

17- Kuhr A, Popa-Wagner A, Schmoll H, Schwahn C, Kocher T. Observations on experimental marginal periodontitis in rats. J Periodontal Res. 2004;39(2):101-6.

18- Leitão RF, Rocha FA, Chaves HV, Lima V, Cunha FQ, Ribeiro RA, et al. Locally applied isosorbide decreases bone resorption in experimental periodontitis in rats. J Periodontol. 2004;75(9): 1227-32.

19- Nassar CA, Nassar PO, Nassar PM, Spolidorio LC. Selective cyclooxygenase-2 inhibition prevents bone resorption. Braz Oral Res. 2005;19(1):36-40.

20- Nociti FH Jr, Nogueira-Filho GR, Primo MT, Machado MA, Tramontina VA, Barros SP, et al. The influence of nicotine on the bone loss rate in ligature-induced periodontitis. A histometric study in rats. J Periodontol. 2000;71(9):1460-4.

21- Sallay K, Sanavi F, Ring I, Pham P, Behling UH, Nowotny A. Alveolar bone destruction in the immunosuppressed rat. J Periodontal Res. 1982;17(3):263-74.
22- Soletti AC, Gaio EJ, Rösing CK. Effect of neonatal clomipramine in the pathogenesis of ligature-induced periodontitis in Lewis rats. Acta Odontol Scand. 2009;67(2):94-8.

23- Souza DM, Ricardo LH, Kantorski KZ, Rocha RF. Influence of alcohol consumption on the alveolar bone level associated with ligature-induced periodontitis in rats. Braz Oral Res. $2009 ; 23(3): 326-32$

24- Souza DM, Ricardo LH, Prado Mde A, Prado Fde A, Rocha RF. The effect of alcohol consumption on periodontal bone support in experimental periodontitis in rats. J Appl Oral Sci. $2006 ; 14(6): 443-7$

25- Souza DM, Rocha RF. Low caloric value of ethanol itself increases alveolar bone loss in ligature-induced periodontitis in male rats. Braz Oral Res. 2009;23(4):460-6.

26- Tatakis DN, Guglielmoni P. HLA-B27 Transgenic rats are susceptible to accelerated alveolar bone loss. J Periodontol. $2000 ; 71(9): 1395-400$.

27- Verzeletti GN, Gaio EJ, Rösing CK. Effect of methotrexate on alveolar bone loss in experimental periodontitis in Wistar rats. Acta Odontol Scand. 2007;65(6):348-51.

28- Weinberg MA, Bral M. Laboratory animal models in periodontology. J Clin Periodontol. 1999;26(6):335-40. 